\title{
Pensando a formação de professores em artes visuais: Possibilidades de uma docência-artística
}

\begin{abstract}
RESUMO: Esse texto apresenta algumas considerações a respeito da formação de professores em artes visuais e a possibilidade de se pensar em uma formação docenteartística. Considera-se, sobretudo aquilo que os acadêmicos produzem em outros espaços que não somente os institucionalizados das artes visuais e da docência, mas que de alguma forma, participam de seus processos de construção durante o período vivenciado nos cursos de Licenciatura em Artes Visuais.
\end{abstract}

Palavras-chave: formação de professores, docência-artística, processos artísticos.

ABSTRACT: This text presents some considerations regarding teacher training in visual arts and the possibility to think of an artistic-teacher training. The considerations are mainly going to focus on what academics produce in other spaces besides those of institutionalized visual arts and teaching, but somehow integrate their construction processes during the Bachelor's degree courses of Visual Arts.

Keywords: teacher training, artistic-teaching, artistic processes.

Diversas situações são possíveis quando buscamos por uma formação de Licenciatura em Artes Visuais. Muitas negociações são estabelecidas nesse processo de construção. Sou formado em Artes Visuais - Licenciatura plena em Desenho e Plástica pela Universidade Federal de Santa Maria e nesse lugar considero ter adquirido uma formação artística e docente, pois estive durante quatro semestres dentro de um ateliê investigando meu processo artístico, assim como durante quatro semestres estive em estágio investigando meu processo de formação docente.

Em minhas práticas artísticas o meu interesse sempre esteve enredado pelas relações dúbias, pelos tecidos que provocam diferentes sensações ao toque, as cores e as palavras bordadas. Interessa-me, sobretudo a aproximação do público com o objeto, da manipulação, da quebra do ambiente estático que se configura muitas vezes uma sala de exposição. 


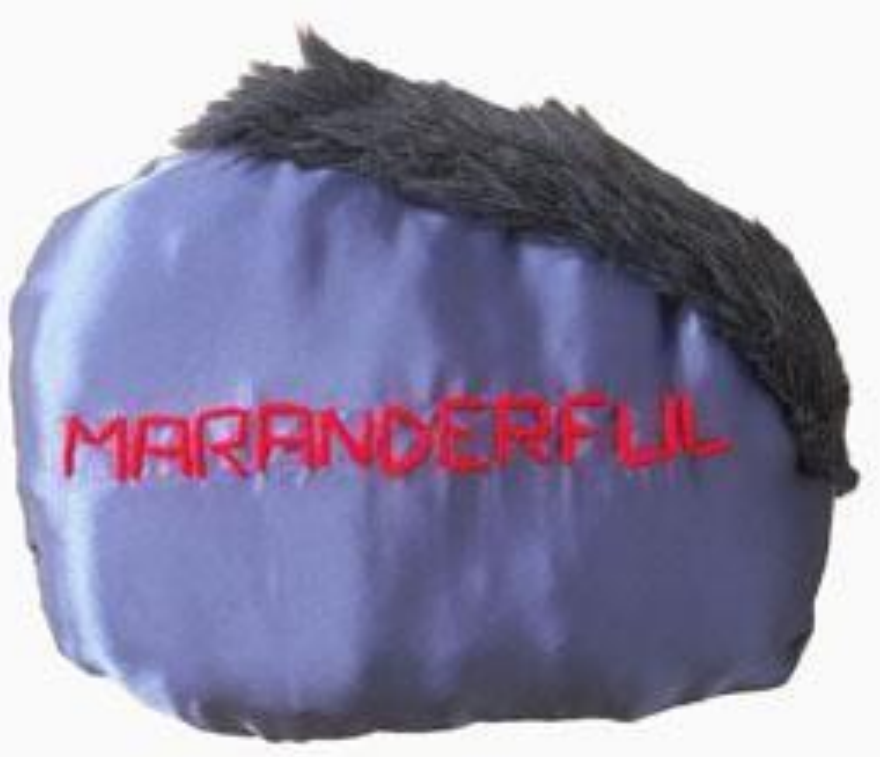

Figura 1. Maranderful, 2010

Arquivo pessoal

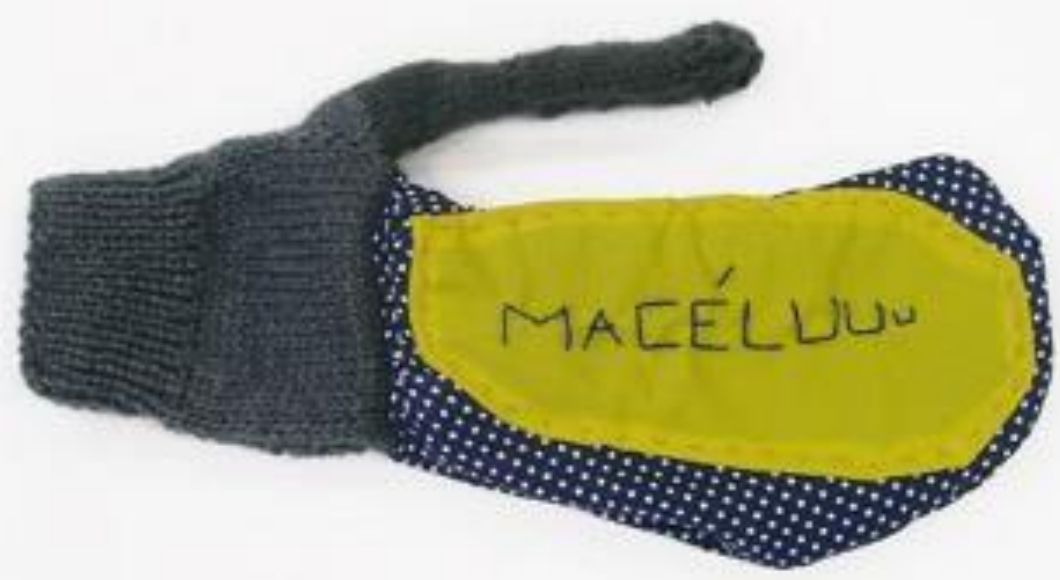

Figura 2. Macéluuu, 2008

Arquivo pessoal 
Busquei nessa produção dispositivos que me proporcionassem pensar em planejamentos de aulas, para que eu pudesse trabalhar durante o estágio. Assim, encontrei possibilidades de falar sobre arte participativa, sobre os cinco sentidos explorados por artistas na construção de suas obras e os modos de ver e de sentir que o público deposita sobre tais produções. Como em uma via de mão dupla agreguei às minhas produções artísticas diversas situações vivenciadas nos espaços educacionais que frequentei enquanto professor.

Com isso, venho ao longo do mestrado no Programa de Pós-Graduação em Arte e Cultura Visual da Universidade Federal de Goiás, discutindo essa questão que esteve presente em minha formação inicial, expandindo meu olhar e explorando outras construções possíveis nesse processo de formação docente-artística. Este texto é um recorte de minha dissertação, ainda em construção e, portanto, sem dados referentes a ida à campo e ao que foi produzido nesse espaço.

Coloco-me no texto na posição de aluno, que fui recentemente durante a graduação e que sou atualmente no mestrado, e como pesquisador que, embora ainda em um processo inicial, me vejo como um, pois penso que as práticas de pesquisa acontecem em diversos aspectos e instâncias de nossas vidas.

\section{Construções e trajetos}

Sua vida é obra de arte, a vida dos outros é obra de arte, a vida dos outros e a sua vida são campos de experimentação.

(PEREIRA, 2010)

Escolher estudar licenciatura significa envolver-se com questões educacionais do ensino formal, não-formal ou informal. Porém, esse envolvimento não exclui a possibilidade do acadêmico desejar as Artes Visuais para além da licenciatura. Não de forma excludente, mas tramando ao longo da trajetória do curso exercícios nos dois campos, que embora distintos, podem se conectar.

E é essa conexão que me lança à pesquisa, a querer aprofundar esses caminhos de uma formação inicial docente em Artes Visuais. Uma docência-artística, que esteja 
permeada pela interdisciplinaridade e que possibilite ao acadêmico inventar suas práticas de maneira rizomática, contaminando-se e produzindo-se com cada um dos campos.

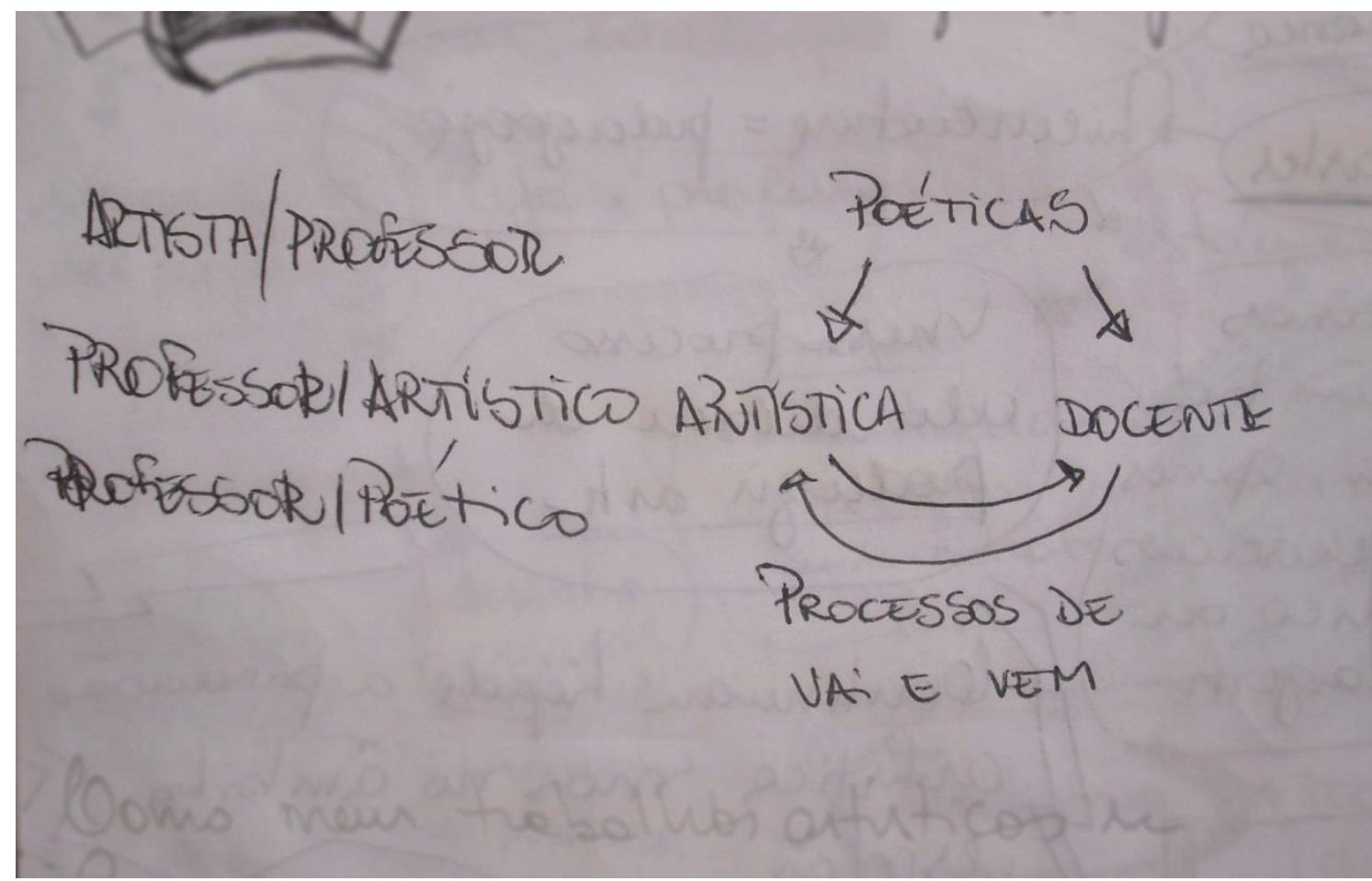

Figura 3. Caderno de pesquisa Fonte: arquivo pessoal.

A figura 3 aponta algumas borbulhas que estiveram presentes no início desse processo de pensar a formação docente-artística e que seguem instigando o pensamento reflexivo acerca das possibilidades de formação no campo da docência em artes visuais.

Trata-se de tomar a poética que prioritariamente está para as artes e lançar-Ihe para a docência, tramando, conectando, intersectando uma instância com a outra. Assim teríamos alguns termos como artista-professor, professor-artista, professor-artístico, professor-poético, etc. Escolhi trabalhar a partir das expressões professor-artista e docência-artística.

Quando falo de professores-artistas não estou necessariamente abordando o professor da educação formal que também é artista inserido no campo institucionalizado das Artes Visuais. Um professor que também é artista para mim é aquele que antes de pensar que técnica, ou que linguagem artística utilizar em suas aulas, pensa de que maneira pode afetar seus alunos, se aproximar deles e que se permite inventar e reinventar a partir de proposições já gastas do ambiente escolar, através de 
Práticas que desfazem a compreensão, a fala, a visão e a escuta das mesmas coisas, dos mesmos sujeitos, dos mesmos conhecimentos. Desassossegam o sossego dos antigos problemas e das velhas soluções. Estimulam outros modos de ver e ser visto, dizer e ser dito, representar e ser representado. (CORAZZA, 2001, p. 30)

Nesse caminho, buscando a partir de Deleuze e Guattari, cheguei às questões que permeiam a desterritorialização, que para mim, tornou-se cada vez mais instigante pensala para essa proposição.

Jamais nos desterritorializamos sozinhos, mas no mínimo com dois termos: mão-objeto de uso, boca-seio, rosto-paisagem. E cada um dos dois termos se reterritorializa sobre o outro. De forma que não se deve confundir a reterritorialização com o retorno a uma territorialidade primitiva ou mais antiga: ela implica necessariamente um conjunto de artifícios pelos quais um elemento, ele mesmo desterritorializado, serve de territorialidade nova ao outro que também perdeu a sua. Daí todo um sistema de reterritorializações horizontais e complementares, entre a mão e a ferramenta, a boca e o seio (DELEUZE; GUATTARI, 1996, p. 41).

Há nesse processo no mínimo duas ações. Uma que é a desterritorialização, em que determinado território usa de sua fluidez, escorregando pelas fronteiras e as ultrapassando. E ao sair dessas fronteiras segue para a segunda ação, a reterritorialização, no encontro e no atravessamento com outro território. No entanto, Deleuze (1988, p. 4) sinaliza que "não há território sem um vetor de saída do território e não há saída do território, ou seja, desterritorialização, sem, ao mesmo tempo, um esforço para se reterritorializar em outra parte".

Por isso, é preciso o desejo e o ato de desterritorializar para que haja a reterritorialização, e essa pode tomar diversos caminhos. Nesta proposição busco o caminho da interseção docente-artística, então, minhas tramas e o esforço da reterritorialização se dão nesse sentido.

Poderíamos entender o território como um espaço físico, como em muitos casos o é, porém, aqui há um deslocamento da expressão para instâncias que não necessariamente 
estão estabelecidas em um território, mas que subjetivamente ocupam espaço em seus campos de atuação, que são o artístico e o docente.

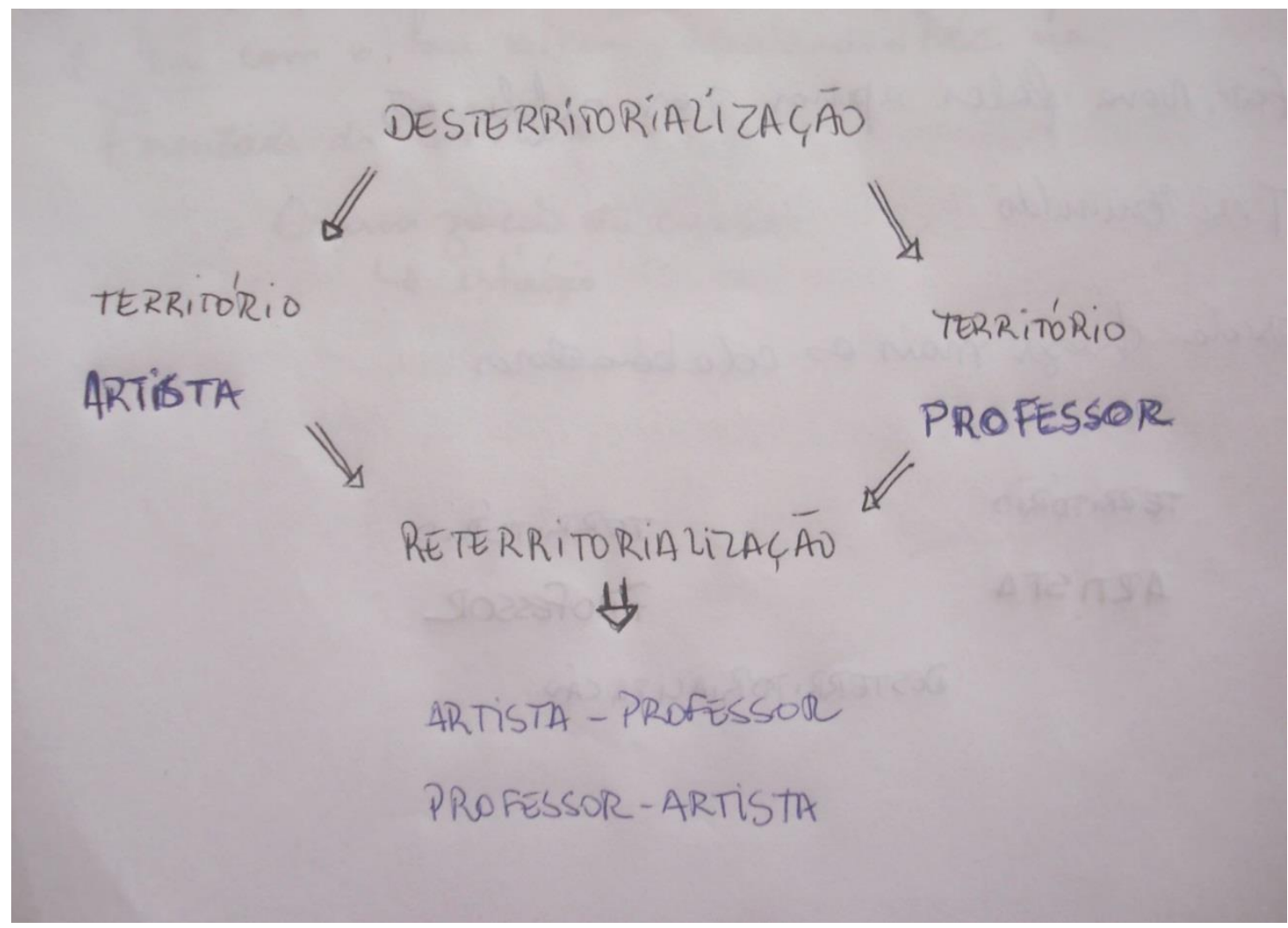

Figura 4. Caderno de pesquisa

Fonte: arquivo pessoal.

Cada um desses territórios carrega consigo uma história e um repertório próprios de suas designações. O que se quer com a desterritorialização é que essas características fixadas em cada um deles permita-se desconjuntar-se para buscar no outro, novos repertórios, reorganizando e inventando um outro território.

No esquema da figura 4 há com a reterritorialização pelo menos dois novos territórios, o do artista-professor e o do professor-artista. Como me proponho pensar acerca da formação de professores em Artes Visuais, priorizo o termo professor-artista, por entender que ele indica uma docência que se manifesta juntamente de processos artísticos/subjetivos/poéticos. Diferentemente do artista-professor, que no meu ponto de vista está direcionado ao profissional que assume as responsabilidades de artista que produz para o meio artístico e de professor que produz para o meio docente.

Não quero dizer com isso, que o artista-professor não possa trilhar um caminho parecido com o do professor-artista, mas entendo que o segundo atende aos meus anseios 
de pesquisa, no que diz respeito às práticas desenvolvidas pelo acadêmico em formação e pelo profissional na área de atuação.

Um professor-artista pode ser aquele que encara duas profissões, a de artista e a de professor, mas também pode ser aquele que produz subjetividades no envolvimento com práticas artísticas sem que necessariamente elas recebam o nome de arte, que de alguma forma contaminem outros espaços desse professor-artista, espaços da sala de aula, que se incorporem aos seus planejamentos e às suas atividades enquanto professores.

O professor-artista possui campos de experimentação, como fala Pereira (2010) onde se encontra em processos individuais, coletivos, de participação, de interferências, de silêncios e de vozes que permeiam produções poéticas, reinvenções de suas próprias práticas e das práticas dos outros. Então, poderíamos pensar não somente no professorartista que desenha, que pinta, que entalha, mas também naquele que tem uma maneira de organizar sua casa, seus livros, suas escritas, nos atos performativos de receber pessoas, de cozinhar e de contar uma história.

Pessi (2002, p. 27) ressalta que "a maneira como cada um de nós ensina está diretamente dependente daquilo que somos como pessoa quando exercemos o ensino". Aquilo que está presente em nosso cotidiano em determinado espaço, reverbera sobre outro, e sobre outro, e assim por diante, tornando nossas experiências e a maneira com que atuamos contaminadas, impuras, enriquecidas por outras situações.

As ações artísticas desses campos de experimentação, embora não estejam na esfera institucionalizada das artes visuais, provocam em algumas pessoas um fazer sensível e poético, envolvendo-as subjetivamente, assim como poderia ser no desenvolvimento de um objeto artístico, de uma ação performática ou de uma instalação.

Há ainda outras características a partir de diferentes pontos de vista, de autores que também buscam por imbricamentos de docência e arte. Corazza (2012, p. 7), por exemplo, fala de professores em devir-simulacro.

Tal devir-simulacro é composto por processos transversais de artistagem, que permeiam as diferentes subjetividades dos educadores, instauram-se através de cada um deles e dos grupos sociais, realizando uma crítica radical a essas formas determinadas e funções legitimadas. 
É uma multiplicidade de formas em uma complexidade de sujeitos. É como Corazza aponta, um desencadeamento de devires que são postos no sujeito professorartista em suas diferentes atuações. Desde suas atividades em sala de aula, em suas pesquisas, em seus arranjos ou em seus trabalhos artísticos, esses devires múltiplos atravessam o educador.

Esses atravessamentos permitem que cada aula seja uma aula e não a aulamodelo, a aula-tradicional ou a aula-conceitual. Uma aula que formule alternativas outras para pensar, que desconstrua o senso comum e que problematize com o aluno quais outros pontos de vista são possíveis em determinadas situações.

É, portanto, uma postura docente-artística que se faz presente no ser professor, que estimule "outros modos de ver e ser visto, dizer e ser dito, representar e ser representado" (CORAZZA, 2001, p. 03).

Loponte em sua tese de doutorado, ao tratar de questões como a docência em arte e as relações de gênero, propõe a expressão docência artista, "constituída através da escrita de si e relações de amizade, como formas possíveis de resistência, de subversão aos poderes subjetivantes [...]" (2005, p. 9)

A autora sugere esse termo como forma de reinvenção das práticas escolares, mas, sobretudo, as práticas das próprias professoras ${ }^{1}$ envolvidas nesse processo, a fim de escapar de modelos prontos e tão enrijecidos no âmbito escolar. É um "modo de ser docente que seja ele mesmo mais artista" (Ibid., p. 73). Há nessa afirmação, uma proposição de trazer para o campo docente o próprio processo do artista que desenha, apaga, desenha novamente, sobrepõe materiais, inquieta-se com os resultados e tenta novamente.

Um ser/estar artista de si e daquilo que os outros o provocam a ser. Um processo de subjetivação que subverte práticas endurecidas, relacionadas no caso da pesquisadora com questões de gênero e poder, engendrando novos modos de ser.

Inventamos e reinventamos juntas esses modos de subjetividade ético-estética que, por vezes, estão ausentes dos programas de formação docente. Escapamos, desviamos das relações de poder e saber que envolvem relações de gênero, por exemplo, e que insistem para que as professoras se conformem no papel de

\footnotetext{
${ }^{1}$ A pesquisa foi realizada com um grupo de professoras da Universidade de Santa Cruz do Sul.
} 
"professorinhas", devoradoras ávidas de receitas prontas e acabadas para suas aulas. (Ibid., p. 91)

Em geral, esses processos de imbricamentos de docência e arte não se resumem às linguagens artísticas tal como a pintura, a escultura ou a performance. Aqui, para esse momento, busco tratar de situações artísticas/poéticas/subjetivas (não necessariamente nessa ordem), que se manifestem a partir dos sujeitos ou a partir da natureza, do cotidiano, de situações que provoquem em nós seres humanos, experiências afetivas, sensações que nos envolvam e que nos façam refletir.

A prática docente requer uma reflexão constante sobre conteúdos, procedimentos, recursos, posturas do professor; requer também a superação de um viver a maior parte do tempo de modo inconsciente. (PESSI, 2002, p. 20-21)

A subjetivação dessas diferentes atividades que nos tocam, pensadas também enquanto processos artísticos podem vir a ser tomadas como pesquisa na formação do professor-artista, a partir de suas metodologias, das escolhas de imagens, linguagens e materiais trabalhados com os alunos.

Nas últimas décadas, tornaram-se cada vez mais comuns projetos, programas e propostas que buscam estabelecer correlações entre pesquisa científica e práticas artísticas, num esforço quase sempre profícuo de aproximações entre os modos de conhecer dos procedimentos científicos e das práticas artísticas. Resultam, então, metodologias diversas de pesquisa, orientações epistemológicas, concepções do ato de conhecer, cujos pontos de vista tendem a uma natureza híbrida, capaz de lidar com rigor e liberdade na criação, experiência estética e artística, e conhecimento. (MARTINS et al. 2011, p. 226/227) 
O processo de formação docente, contaminado pelas práticas artísticas e ainda pelas outras experiências presentes em outros contextos da vida do acadêmico, é também um processo de pesquisa, de compreensão, de desenvolvimento de didáticas e práticas docentes e de interação com os diferentes espaços da educação, neste caso, da educação das artes visuais.

Porém, até as primeiras décadas do século $X X$ havia e frequentemente ainda há o pensamento de que ser professor é ser alguém imbuído de conteúdos que chega na sala, pede silêncio, escreve no quadro, dita exercícios para que os alunos apreendam, aprendam e executem. Mas, as diferentes mudanças que aconteceram no Brasil desde então, e as transformações que vem acontecendo dia-a-dia afetam de alguma maneira os vários campos, seja da política, da economia, da ciência ou da educação.

Na sociedade contemporânea, as rápidas transformações no mundo do trabalho, o avanço tecnológico configurando a sociedade virtual e os meios de informação e comunicação incidem com bastante força na escola, aumentando os desafios para torná-la uma conquista democrática efetiva. (PIMENTA; LIMA, 2011, p.

89).

Na educação das artes visuais, participar dessas mudanças é compreender o aluno não somente como alguém que precisa de nossos ensinamentos, que necessita receber, mas como um ser humano que também tem suas escolhas, também sabe articular preferências e pode contribuir conosco e com os espaços que compartilhamos.

Durante o período de formação há disciplinas que provocam embates, que desestabilizam e colocam em dúvida as crenças dos acadêmicos com relação à escola, às pessoas de uma maneira geral e a eles mesmos. Quando entramos no curso, por exemplo, muitos de nós acreditamos possuir o dom, ou o talento nato que nos coloca no caminho das artes visuais. Porém somos levados a duvidar e rever nossas posturas.

Assim como, em disciplinas pedagógicas passamos a ver as questões da escola de uma outra perspectiva, diferente da que conhecíamos enquanto alunos da educação básica. Somos novamente instigados a descobrir outros aspectos e reavaliar posicionamentos no que tange a formação docente e os seus espaços de vivência.

Hernández (2005, p. 29) enfatiza que "ser docente, pai e mãe não são realidades essenciais, senão sociais, discursivas, e como tais, modificáveis, produto de cada época e 
contexto". E no que diz respeito a essas identidades que se configuram e se conformam no decorrer do curso, ainda é possível falar a partir de Hall (2006) que durante muito tempo elas foram encaradas como fixas, e os sujeitos unificados, mas, vêm passando por um processo de transformação, fazendo assim surgir identidades fragmentadas, em constantes mudanças.

\section{Para outras miradas}

A carga de significados que as expressões professor e artista possuem, constrói um imaginário. Muitas vezes esse imaginário é o professor como aquele que é responsável por ensinar, fazer-se entender e fazer com que os alunos entendam o conteúdo a ser passado, e o artista aquele que é livre para se expressar, que pode viajar em pensamentos e produzir subjetivamente aquilo que compreende da vida.

De certa forma não é um julgamento errado, é apenas um mau julgamento, uma forma reduzida de ver essas duas instâncias. São características que não se resumem a elas mesmas, pois cada ser humano possui características diferentes que independem da profissão que escolhem. São identidades em construção permanente. Hall trata essa questão como um processo em andamento.

[...] A identidade é realmente algo formado, ao longo do tempo, através de processos inconscientes, e não algo inato, existente na consciência no momento do nascimento [...] ela permanece sempre incompleta $[\ldots]$ (HALL, 2006, p. 38).

O autor complementa ainda que a identidade se forma a partir de "uma falta de inteireza" (Ibid. p. 39). E nesse sentido, podemos pensar as profissões de professores e de artistas também como algo incompleto, que depende do indivíduo que assume esse corpo artístico ou corpo docente construir sua identidade, através de suas subjetividades e de seus devires.

Bem como, o professor-artista ou o artista-professor reterritorializados, não são processos acabados, resolvidos. Não se dá por encerrada a questão unindo o ser artista ao 
ser professor, porque mesmo que se estabeleçam dois novos territórios, esses ainda assim serão vazados, possuirão brechas para que outras contaminações sejam possíveis.

Entendendo que nossas formações se dão enquanto processos, de que maneira podemos pensar a formação de professores-artistas? Acadêmicos passando por experiências de ateliê, buscando aprofundamentos em determinada linguagem, técnica ou por questões conceituais de seu objeto artístico? Ou aquele que mesmo não experienciando determinadas linguagens na universidade busca paralelamente desenvolver um trabalho, seja em casa em suas práticas cotidianas, em um caderno de desenho, ou em um coletivo de arte com intervenções no espaço urbano? Ou mesmo em disciplinas pedagógicas, quando tem a possibilidade de se reportar a outras situações que permitam pensar a escola, a educação, as artes visuais de uma maneira subjetiva, ampliada, inventiva?

Costurar, amarrar, emendar todas essas interrogações para que se produza uma afirmação de como se constrói uma docência-artística, é possível? Se tudo é construção, acredito que podemos temporariamente nos apropriar dessas indagações e trazê-las enquanto meios de pensar uma formação que docente, também se faz artística.

\section{Referências}

CORAZZA, Sandra. Na diversidade cultura, uma docência artística. Pátio - revista pedagógica. Porto Alegre, Ano V, no 17, 2001.

CORAZZA, Sandra M. Contribuições de Deleuze e Guattari para as pesquisas em educação. In: Revista Digital do LAV. No 8, 2012.

DELEUZE, Gilles. O abecedário de Gilles Deleuze: transcrição integral do vídeo, para fins exclusivamente didáticos. Éditions Montparnasse: Paris, 1988.

DELEUZE, Gilles; GUATTARI, Félix. Mil Platôs: capitalismo e esquizofrenia. Vol. 3. Rio de Janeiro: Ed. 34. 1996.

HALL, Stuart. A identidade cultural na pós-modernidade. Rio de Janeiro: DP\&A, 2006.

HERNÁNDEZ, Fernando. A construção da subjetividade docente como base para uma proposta de formação inicial de professores de Artes Visuais. In: OLIVEIRA, Marilda de O; 
HERNÁNDEZ, Fernando. (orgs) A formação do professor e o ensino das artes

visuais. Santa Maria, Ed. UFSM, 2005. P. 22-42

LOPONTE, Luciana G. Docência artista: arte, estética de si e subjetividades femininas. 2005.f. Tese (Doutorado) - Faculdade de Educação, Universidade Federal do Rio Grande do Sul, Porto Alegre, 2005.

MARTINS, Alice Fátima et al. Portal L: entre-lugares, (des)encontros possíveis. In: Anais do $\mathbf{2 0}^{\circ}$ Encontro Nacional de Pesquisadores em Artes Plásticas. Disponível em <http://www.anpap.org.br/anais/2011/index.html> Acessado em 02/04/2012.

PEREIRA, Marcos Villela. Pesquisa em educação e arte: a consolidação de um campo interminável. In: Revista Iberoamericana de Educación, Núm. 52, janeiro-abril, 2010, p. 61-80. Disponível em

<http://redalyc.uaemex.mx/src/inicio/ArtPdfRed.jsp?iCve=80013049002 > Acessado em $08 / 11 / 2011$

PESSI, Maria C.A.S. Experiência Estética: Constituindo Professores de Arte. In: Revista Nupeart, vol. 1. 2002. Disponível em http://www.periodicos.udesc.br/index.php/nupeart/article/viewFile/3032/2234 acessado em $02 / 02 / 2012$

PIMENTA, Selma G.; LIMA, Maria S.L. Estágio e docência. São Paulo: Cortez, 2011.

Marcelo Forte (UFG)

Recebido em: 27/10/2012

Aprovado em: $17 / 01 / 2013$ 